\title{
Anesthesia research in Japan: seeds of recovery and the role of the Journal of Anesthesia
}

\author{
Kazuyoshi Hirota ${ }^{1}$ (D)
}

Received: 23 April 2017 / Accepted: 27 May 2017 / Published online: 2 June 2017

(C) Japanese Society of Anesthesiologists 2017

\section{To the Editor:}

Nature Index 2017 data clearly show that the absolute number of scientific publications from Japan has declined from 2005 to 2015. The share of the world's science output from both the USA and the UK has also fallen but the decline is only relative to the output from China, which rose steeply by $\sim 300 \%$ between 2005 and 2015 in the Web of Science (WOS) [1]. Although the decrease from Japan for these 10 years was $<1 \%$ in the WOS, Japan's share of the world's scientific output markedly decreased from 8.4 to $5.2 \%$. Nature Index also shows a reduction in Japan's contribution to scientific output by $19.6 \%$ between 2012 and 2016. This stagnation is of major concern to Japanese scientific researchers.

What is the situation for medical science in Japan? In previous editorials [2, 3], I showed that medical publications from Japan, particularly clinical research papers, dramatically decreased. Factors explaining the reduction were (1) the introduction of a new postgraduate clinical training system in 2004 reduced the supply of qualified physician for clinical practice with a 'knock-on' effect on research time, and (2) the loss of the scientific education system for the first 2 years as a result of the new clinical training system reduced research interest in our residents. With the consistent intervention of each clinical medical society, our recent world ranking for publications in major clinical medical journals such as New Engl J Med, Lancet and JAMA is beginning to recover from 25th in 2008-2011 to 19th in 2013-2014. However, the ranking for

Kazuyoshi Hirota

hirotak@hirosaki-u.ac.jp

1 Department of Anesthesiology, Hirosaki University Graduate School of Medicine, Hirosaki 036-8562, Japan those in the major basic medical journals such as Nat Med, Cell, and J Exp Med showed a small decrease from 4th to 6th position (data from WOS).

Regarding anesthesia research, I have previously reported a major crisis in Japan [2-4]. The total number of publications in 3 major anesthesia journals (Br J Anaesth, Anesthesiology and Anesth Analg) has fallen precipitously by $75 \%$ since 2003 . The Japanese Society of Anesthesiologists (JSA) has expressed serious concern about this fall. As a consequence, the JSA immediately took measures in an attempt to rectify the situation. The JSA launched JA Clinical Reports to increase the opportunity, particularly for junior anesthetists, to write scientific papers in English in areas relevant to their daily clinical practice; effectively returning the research ethos to medicine. In addition, the JSA has established the Research Promotion Committee to offer financial support for anesthesia research in Japan.

In the remainder of this editorial, I would like to assess the recent status of medical and anesthesia publications, particularly from Japan, following the JSA intervention.

Based on the analysis presented here, I was heartened to see that there is evidence of improvement, i.e., 'seeds of recovery'. Since 2012, a V-shaped recovery has been achieved in the total number of publications from Japan in all 30 anesthesia journals categorized by Journal Citation Reports (Br J Anaesth, Anesthesiology, Anesth Analg, Anaesthesia, Eur J Anaesthesiol, Can J Anaesth, Anaesth Intensive Care, J Clin Anesth, Reg Anesth Pain Med, Curr Opin Anaesthesiol, Anaesthetist, Acta Anaesthesiol Scand, Minerva Anestesiol, J Cardiothorac Vasc Anesth, J Neurosurg Anesthesiol, Int J Obstet Anesth, J Clin Monit Comput, Paediatr Anaesth, BMC Anesthesiol, J Anesth (JA), Rev Bras Anestesiol, Ann Fr Anesth Reanim, Anasthesiol Intensivmed Notfallmed Schmerzther, Pain, Eur J Pain, Clin J Pain, Pain Pract, Pain Physician, Schmerz). In addition, the 

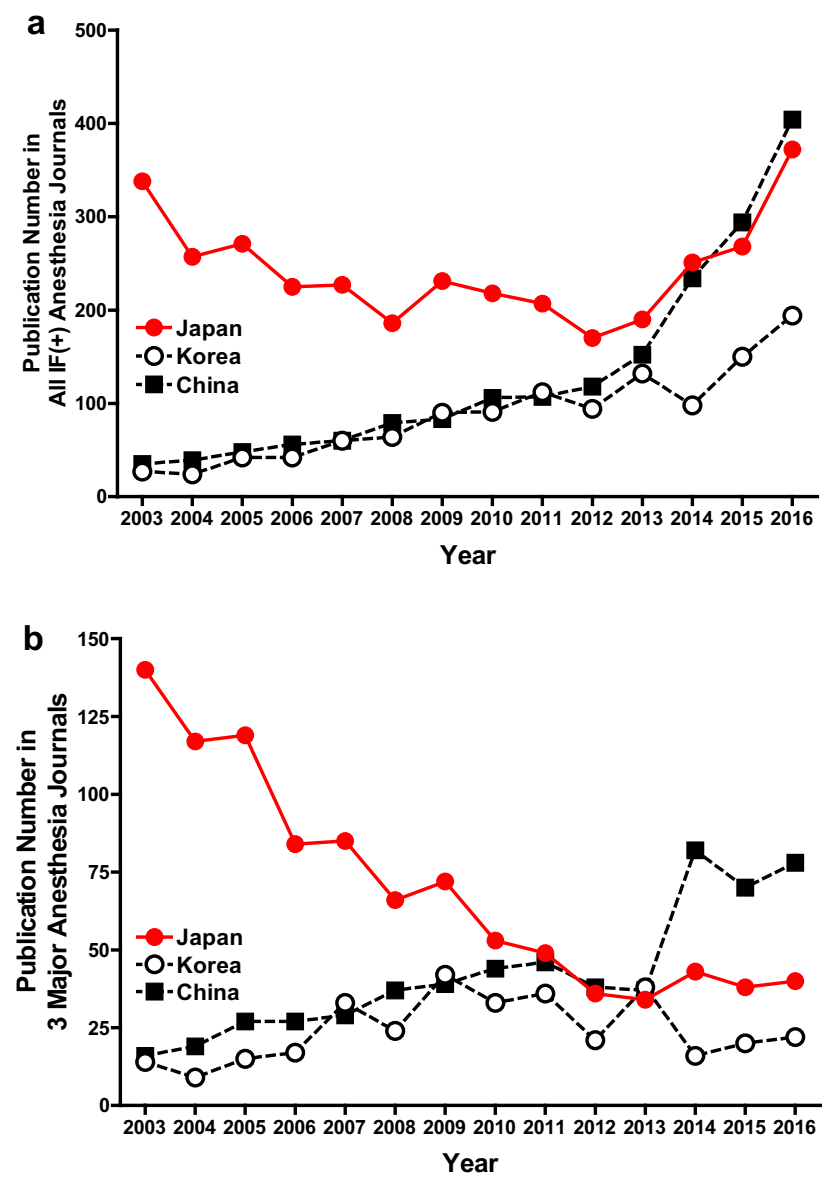

Fig. 1 Annual changes in publication numbers from East Asian countries in a all anesthesia journals categorized by Journal Citation Reports (Br J Anaesth, Anesthesiology, Anesth Analg, Anaesthesia, Eur J Anaesthesiol, Can J Anaesth, Anaesth Intensive Care, J Clin Anesth, Reg Anesth Pain Med, Curr Opin Anaesthesiol, Anaesthetist, Acta Anaesthesiol Scand, Minerva Anestesiol, J Cardiothorac Vasc Anesth, J Neurosurg Anesthesiol, Int J Obstet Anesth, J Clin Monit Comput, Paediatr Anaesth, BMC Anesthesiol, J Anesth (JA), Rev Bras Anestesiol, Ann Fr Anesth Reanim, Anasthesiol Intensivmed Notfallmed Schmerzther, Pain, Eur J Pain, Clin J Pain, Pain Pract, Pain Physician, Schmerz), and b 3 major anesthesia journals $(\mathrm{Br} J$ Anaesth, Anesthesiology and Anesth Analg)

total number is moving closer to those from China (Fig. 1a). The number of JSA members has increased by 3700 since 2003 (Fig. 2a), and total publication/100 JSA members also displayed a V-shape recovery since 2012 (Fig. 2b). However, Fig. 1b shows that publication output to 3 major anesthesia journals has yet to recover. Compared to 2003 data, the total number of publications from Japan in those 3 major journals reduced by $75 \%$ in 2012 and has not increased so far, although there was a small increase from Korea. In contrast, those from China markedly increased by about $400 \%$ in 2016, and the absolute number of publications also exceeded those from Japan since 2012, with an increase in the difference between our two countries.
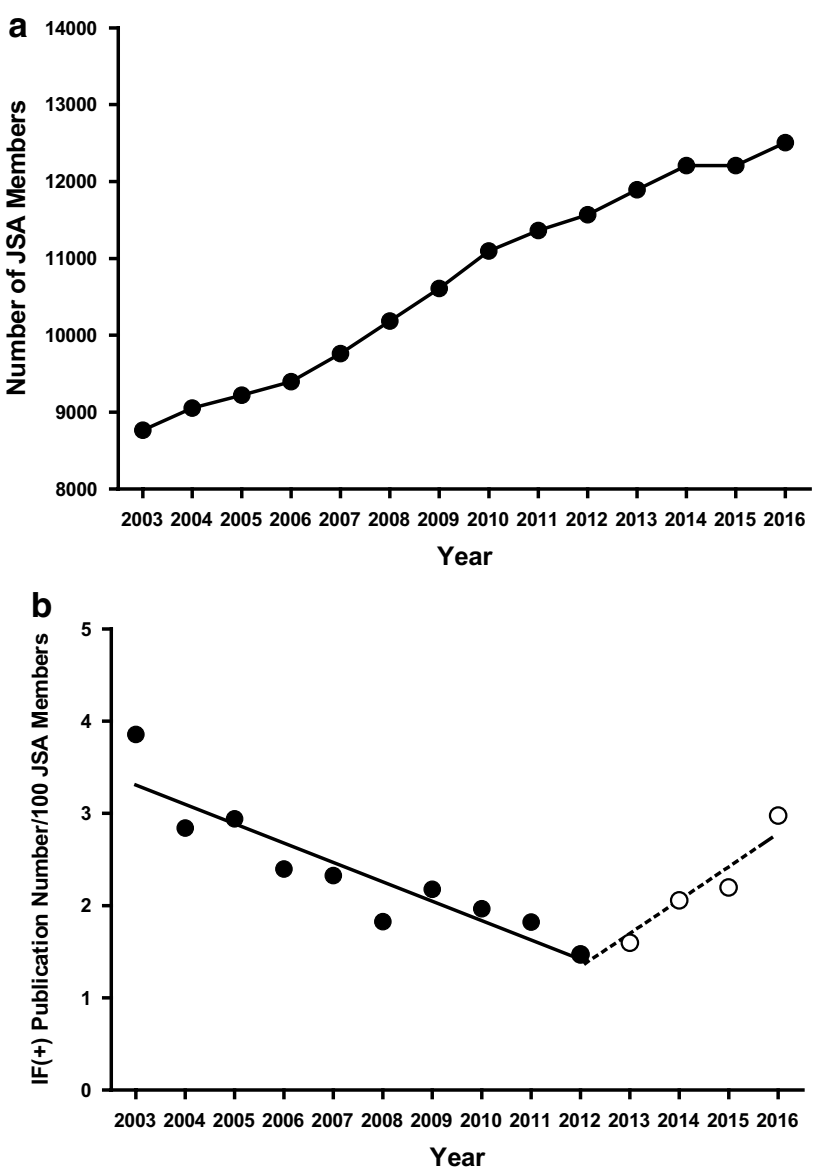

Fig. 2 Annual changes in numbers of a Japanese Society of Anesthesiologists (JSA) members and b total publication numbers/100 JSA members

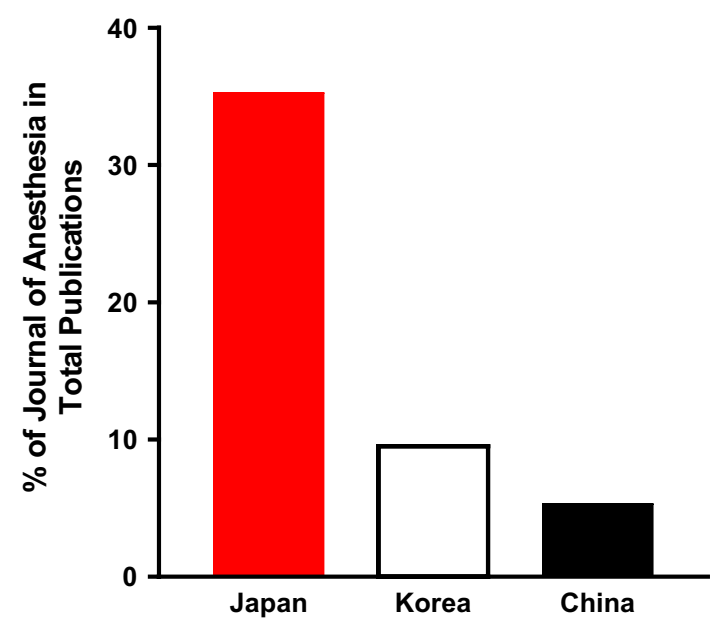

Fig. 3 The share (\%) of 'Journal of Anesthesia' in the total output of anesthesia journals listed in Journal Citation Reports from East Asian countries 
Approximately one-third of papers from Japan have been published in JA while only 5\% from China have been published in our journal (Fig. 3); however, this may relate to the fact that JA is the official journal of the JSA. This clearly suggests that JA has propped up anesthesia publications from Japan. However, the fact that publication numbers from Japan in 3 major journals has not yet recovered suggests that high-quality anesthesia research activities in Japan has also yet to recover. As JA has the highest publication output from Japan, improvements in the quality of Japanese anesthesia research may reflect on the quality of JA with an increase in its Impact Factor. Thus, the JSA should continue to support Japanese anesthesia researchers in this mutually beneficial activity. I hope that the efforts of the JSA will continue to be strong and will help in reviving Japanese anesthesia research activity. JA always looks forward to receiving highquality submissions from JSA members as your official journal.

\section{References}

1. Phillips N. Striving for a research renaissance. Nature. 2017;543:S7.

2. Hirota K. A worrying decline in anesthesia journal publications from Japan. J Anesth. 2013;27:323-4.

3. Hirota K. Launch of JA clinical reports. Anesthesia research crisis in Japan. J Anesth. 2015;29:161-3.

4. Hirota K. The present crisis of the publication activity in anesthesia research in Japan and its countermeasure. Masui. 2015;64:17-29. 